Disponível em:

http://editora.unoesc.edu.br/index.php/race

Race, Joaçaba, v. 14, n. 1, p. 39-72, jan./abr. 2015

\title{
A DIMENSÃO TÁCITA DO CONHECIMENTO NAS PRÁTICAS CONTÁBEIS: UMA ANÁLISE DOS PROCESSOS DE ELABORAÇÃO E APRESENTAÇÃO DE RELATÓRIOS EM ORGANIZAÇÕES CONTÁBEIS
}

The tacit dimension of knowledge in accounting practices: an analysis of the processes of preparation and presentation of reporting in accounting organizations

\section{Fernando Luís Bertolla \\ E-mail: fernando@cruzeiro.inf.br}

Mestre em Administração pela Universidade de Caxias do Sul; Doutorando em Administração pela associação entre a Universidade de Caxias do Sul e a Pontifícia

Universidade Católica do Rio Grande do Sul; Professor do Centro de Ciências Econômicas, Contábeis e de Comércio Internacional da Universidade de Caxias do Sul.

Ana Cristina Fachinelli

E-mail: afachinelli@gmail.com

Pós-doutora em Inteligência Estratégica pela Universidad de Deusto, Espanha; Doutora em Ciências da Comunicação e da Informação pela Université de

Poitiers; Professora Pesquisadora do Centro de Ciências da Comunicação e do Programa de Pós-graduação em Administração da Universidade de Caxias do Sul; Endereço: Rua Francisco Getúlio Vargas, 1130, Petrópolis, 95070-560, Caxias do Sul, Rio Grande do Sul, Brasil. 


\section{Resumo}

No setor contábil, a elaboração de relatórios e sua apresentação aos clientes não constituem uma prática obrigatória, no entanto, são fundamentais em termos de informações contábeis úteis ao processo gerencial e decisório. A interpretação dos dados e informações contidos nesses relatórios possibilita a construção de estratégias fundamentadas em aspectos concretos do negócio. Entretanto, pela sua não obrigatoriedade, esses processos agregam muito conhecimento tácito desenvolvido e internalizado ao longo do tempo. Esse tipo de conhecimento é difícil de formalizar, comunicar e partilhar com os outros. Assim, o objetivo deste trabalho foi analisar a dimensão tácita do conhecimento, sob a ótica dos elementos de ordem técnica e cognitiva, nos processos contábeis de elaboração de relatórios gerenciais e apresentação dos resultados aos clientes de organizações contábeis. O método utilizado foi um estudo exploratório descritivo a partir do resgate do conhecimento tácito, utilizando o sense-making de Dervin (1983, 1999) e Weick (1995), associado ao método de análise de conteúdo conforme definições de Bardin (1977), Minayo (2004) e Vergara (2008). O estudo foi realizado nas organizações contábeis associadas ao Sescon-Serra Gaúcha, que implantaram o Programa de Qualidade Necessária Contábil (PQNC), categoria ouro. Os resultados indicam que as técnicas de diálogo do sense-making possibilitam a sistematização do resgate do conhecimento tácito que, quando compartilhado, pode influenciar os processos contábeis pela via de suas práticas e pode ser um elemento central para a inovação incremental nos processos contábeis.

Palavras-chave: Conhecimento tácito. Contabilidade. Análise de conteúdo. Sense-making. Relatórios e resultados contábeis.

\section{The tacit dimension of knowledge in accounting practices: an analysis of the processes of preparation and presentation of reporting in accounting organizations}

Abstract

In the accounting sector, preparation and presentation of accounting reports are not required to the practice of accounting processes, however, they are critical in terms of useful accounting information to the management process and also decision-making. The interpretation of data and information contained in these reports enables the construction of strategies based on concrete aspects of the business. On the other hand, what is observed is that the professionals involved in the preparation and presentation of accounting reports have internalized tacit knowledge, which is a differential in terms of both performance and quality of the final work. This knowledge is constructed in the context of the practice. This study aimed to analyze the tacit dimension of knowledge, from the technical and cognitive approach in preparation and presentation of accounting reports to clients. The method used was an exploratory study, using the sense-making of Dervin (1983, 1999) and Weick (1995), associated with the method of content analysis according to the definitions of Bardin (1977), Minayo (2004) and Vergara (2008). The study was conducted in organizations associated with the accounting Sescon-Serra Gaucha, who deployed Quality Program Needs Accounting (PQNC), gold category. The results indicate that the techniques of sense-making dialogue 
allow the systematization of the tacit knowledge that when shared, can influence the accounting processes through their practices and may be a central element for incremental innovation in accounting processes. Keywords: Tacit knowledge. Accounting. Content analysis. Sense-making. Accounting results and reporting.

\section{INTRODUÇÃO}

A contabilidade no Brasil atravessa um momento de mudanças relevantes motivadas principalmente pela adoção do Sistema Público de Escrituração Digital (SPED) e pela busca da harmonização e da convergência das normas contábeis brasileiras aos padrões internacionais de contabilidade. Nesse quadro, a demanda pela informação contábil é crescente e algumas práticas como a elaboração de relatórios gerenciais e a apresentação dos resultados aos clientes têm se configurado como fatores de apoio à gestão. Além disso, tais práticas geram um aprendizado de natureza sobretudo aplicada e uma base de conhecimento cuja dimensão tácita influencia e pode determinar a adaptação das organizações contábeis ao contexto atual.

Polanyi (1966), com a obra The Tacit Dimension, estabelece o princípio fundamental do conhecimento tácito ao afirmar que o ser humano pode saber mais do que pode dizer. Assim, mesmo que a maior parte desse conhecimento não possa ser colocado em palavras, é parte indispensável de todo e qualquer conhecimento.

Segundo Antunes (2000), o conhecimento é um recurso diferenciado e ilimitado, pois à medida que uma pessoa o adquire mais aumenta sua capacidade de desenvolver novos conhecimentos. Essa capacidade acaba por gerar a noção do conhecimento como elemento de valor diferenciado no mundo organizacional nos mais diversos setores. Nos anos 1970, Drucker (1970) já alertava a sociedade para algumas reflexões sobre o futuro. Dizia ele que o surgimento de novas tecnologias mudariam o perfil da indústria, que as mudanças na economia mundial fariam do mundo um só mercado e que o conhecimento se tornaria capital, enquanto recurso econômico. Por isso, os homens de poder seriam os homens de conhecimento.

Especificamente no contexto do setor contábil, a relação entre conhecimento e contabilidade foi pioneiramente abordada na $1^{\mathrm{a}}$ Conferência Ibero-Americana de Ciências Contábeis, realizada em Belo Horizonte, MG, no ano 1993, quando foi discutida a Teoria Geral do Conhecimento Contábil. Essa Teoria parte da compreensão da essência contábil para o seu entendimento racional e do que acontece com a riqueza individual ou de grupos, possibilitando ao contador uma visão global do contexto em que seus trabalhos estão inseridos (SÁ, 1993). O 
conjunto de informações contábeis envolve praticamente todos os aspectos de uma empresa suscetíveis de serem expressos em termos monetários: os ativos ou itens de riquezas; os passivos ou interesses de credores que fornecem dinheiro e mercadorias, ou prestam serviços, e aguardam o pagamento ou a remuneração; e, finalmente, os direitos de proprietários que realizaram investimentos. Enfim, acompanham toda a mutação patrimonial da empresa. Para Iudícibus (2000), a contabilidade e seus relatórios têm como objetivo principal fornecer informações relevantes para que os usuários possam tomar decisões com segurança.

No ano 2007 ocorreram duas mudanças relevantes na contabilidade brasileira. A primeira, o Decreto n. 6.022, de 22 de janeiro de 2007, que institui o Sistema Público de Escrituração Digital (SPED), o qual tem como principal finalidade unificar as atividades de recepção, validação, armazenamento e autenticação de livros e documentos que integram a escrituração comercial e fiscal das empresas (BRASIL, 2007a). A segunda mudança ocorreu por meio da Lei n. 11.638, de 28 de dezembro de 2007, que altera e revoga os dispositivos da Lei n. 6.404, de 15 de dezembro de 1976. Essa alteração introduziu novos dispositivos na Lei das Sociedades Anônimas, entre eles a obrigatoriedade do uso do critério de avaliação de ativos pelo seu valor recuperável e o das depreciações que passam a ser efetuadas com base na vida útil econômica dos bens (BRASIL, 2007b). Destaca-se que essa redução do valor recuperável de ativos é o pronunciamento técnico do Comitê de Pronunciamentos Contábeis (CPC) 01(R1), aprovado pela Deliberação da Comissão de Valores Mobiliários (CVM) n. 639, de 07 de outubro de 2010, e é uma das mais relevantes alterações ocorridas no Brasil, a qual busca o alinhamento e a convergência às normas internacionais de contabilidade, denominadas International Financial Reporting Standards (IFRS), conforme padrões do International Accounting Standards Board (IASB).

Conforme mencionado por Palácios (2010), essas mudanças impõem ao Brasil adotar um padrão internacional para elaborar e divulgar as demonstrações contábeis de suas empresas que a cada dia aumentam a sua participação no mercado internacional. Também destaca que os investidores estrangeiros visualizam o nosso país como uma boa alternativa para a aplicação dos seus recursos. Assim, a comparabilidade da contabilidade brasileira, ou seja, dos seus relatórios, com a contabilidade internacional, tornou-se uma realidade. Em razão dessas mudanças, a demanda pela informação contábil é crescente, tornando-se de fundamental importância o aumento da qualidade das informações proporcionadas. Por meio dessas informações, norteadas pelos princípios fundamentais de contabilidade, o 
contador constrói ao longo do exercício de suas atividades um aprendizado prático. Ao se somar também as experiências vivenciadas, as práticas nutrem a dimensão tácita do conhecimento que se manifesta nos processos contábeis.

O conhecimento tácito é desenvolvido e internalizado ao longo do tempo durante a realização de tarefas específicas. São as maneiras próprias encontradas para solucionar diferentes situações e as diversas experiências adquiridas e construídas. Esse tipo de conhecimento é difícil de formalizar, comunicar e partilhar com os outros. No âmbito da contabilidade, o conhecimento tácito se faz presente em diferentes fases dos processos contábeis. No caso desta pesquisa, o foco se situou especificamente nos processos contábeis de elaboração de relatórios gerenciais e de apresentação de resultados aos clientes das organizações contábeis. São processos que, além de reunir e organizar informações, possuem uma quantidade relevante de conhecimento tácito que merece uma maior discussão.

Mais especificamente na elaboração dos relatórios gerenciais e na apresentação dos resultados, é utilizada uma abordagem voltada não somente para a técnica contábil com suas competências funcionais e pessoais, mas também para as necessidades específicas de cada cliente. O contador necessita amplo entendimento de cada segmento de negócio para que possa adaptar e personalizar os relatórios e sua apresentação conforme as particularidades dos ramos de atividade e seus relacionamentos.

Por isso, no âmbito deste trabalho, postulamos que na apresentação dos resultados há uma relação com a forma de apresentá-los, a qual, além de estar ligada ao cognitivo, pode também estar ligada ao sentido emocional do profissional contábil em relação ao cliente. Por outro lado, o resgate do conhecimento tácito é um processo complexo que não ocorre espontaneamente, principalmente em áreas com características técnicas bem definidas, como é o caso da contabilidade.

Assim, a questão que norteou o presente estudo foi: Como identificar e analisar a dimensão tácita do conhecimento nas práticas contábeis de elaboração de relatórios e apresentação dos resultados?

Consideramos que, na elaboração de relatórios gerenciais e na apresentação dos resultados, seria possível a identificação de dois elementos distintos do conhecimento tácito, conforme Polanyi (1966) e Nonaka (1994), de ordem técnica, que está na base do processo de elaboração dos relatórios gerenciais, e de ordem cognitiva, que está relacionada à apresentação dos resultados.

Assim, o objetivo deste trabalho foi analisar a dimensão tácita do conhecimento, sob a ótica dos elementos de ordem técnica e de ordem cognitiva, 
nos processos contábeis de elaboração de relatórios gerenciais e apresentação dos resultados aos clientes de organizações contábeis. A pesquisa foi desenvolvida por meio de técnicas de diálogo em conjunto com análise de conteúdo, privilegiando análises derivadas do sense-making, que utiliza os fatos para organizar a realidade e, dessa maneira, coloca a informação dentro do seu contexto, atribuindo-lhe sentido (DERVIN, 1983). Os resultados do estudo podem contribuir para uma maior compreensão das técnicas do sense-making para resgatar conhecimentos tácitos dos contadores envolvidos nos processos de elaboração de relatórios gerenciais e apresentação dos resultados. Tal resgate pode possibilitar a construção de uma base de conhecimento orientada por boas práticas para qualificar e agilizar a realização desses processos nas organizações contábeis.

\section{CONHECIMENTO TÁCITO E SENSE-MAKING}

Nas obras de Polanyi $(1958,1966)$, observa-se a contribuição para uma nova compreensão da epistemologia, sobre as duas dimensões de conhecimento, o tácito e o explícito, e sua relação permanente. A dimensão tácita do conhecimento utilizada na interpretação e na produção do conhecimento explícito não pode ser obtida sem que o tácito se constitua como contexto de referência dentro do qual seja possível a sua compreensão. Nonaka e Takeuchi (1997), ao aprofundarem os estudos sobre as dimensões do conhecimento propostas por Polanyi (1966), caracterizam o tácito como pessoal e específico ao contexto e difícil de ser formulado e comunicado, e o explícito, transmissível em linguagem formal e sistemática.

Jimes e Lucardie (2003), em seus estudos, identificaram que a formalização do conhecimento tácito implica processos de resgate e comunicação. Estudos de Garcia-Peres e Mitra (2008), baseados na suposição de Polanyi (1966), classificam o conhecimento como aquele que não pode ser comunicado; o conhecimento que pode ser comunicado, mas não pode ser expresso em documentos (conhecimento tácito); e, o conhecimento que pode ser explicitado e compartilhado por meio da linguagem escrita e incorporado a documentos.

Essas observações a respeito de tipos de conhecimento tendem a confirmar Davenport e Prusak (1998), para os quais o conhecimento adquirido por meio da experiência e que permanece em sua forma tácita nem sempre pode ser expressado pela linguagem, nem incorporado em ferramentas cognitivas, como documentos. 
Outra afirmação desses autores indica que não basta considerar o conhecimento a partir da perspectiva de um indivíduo, mas também como um ativo organizacional.

$\mathrm{Na}$ área da contabilidade, estudos recentes associados ao conhecimento organizacional apontam para a importância de investir e estimular o desenvolvimento do capital intelectual das organizações, conforme Boda e Szlávik (2007), Lopes e Rodrigues (2007) e Beagley, Taylor e Bryson (2009).

Brannstrom e Giuliani (2009) e Joshi e Ubha (2009) enfatizam a necessidade de a contabilidade mensurar e registrar o valor do capital intelectual como ativo intangível, utilizando-se das novas normas International Financial Reporting Standards (IFRS), nas demonstrações contábeis das organizações. Ainda assim, o principal desafio para a compreensão e para a gestão dos ativos intangíveis é a criação coletiva de sentido a partir da aquisição e compartilhamento do conhecimento tácito.

Ao afirmar que o conhecimento não é privado, mas social, Polanyi (1966) busca enfatizar que este é socialmente construído e tem como base a experiência pessoal de cada indivíduo sobre a realidade em que está inserido. Em outras palavras, somente é possível adquirir conhecimento quando o indivíduo se encontra em contato direto com situações que proporcionam experiências inéditas, que são sempre assimiladas a partir dos conceitos internalizados que o indivíduo já dispõe de natureza tácita (GROPP; TAVARES, 2009).

Conforme Polanyi (1966), no momento em que novos conceitos ou palavras são inseridos no sistema de linguagem existente, acabam por se influenciar mutuamente, pois agregam a esse sistema novos conceitos. É assim que todo o conhecimento se fundamenta sobre uma dimensão tácita.

Nonaka (1994) busca expandir o conceito de conhecimento tácito oriundo da abordagem filosófica de Polanyi integrando em sua constituição elementos cognitivos e elementos da técnica. Ou seja, segundo os autores, a dimensão tácita do conhecimento é constituída por dois elementos de ordem distintos: a técnica, compreendendo as competências pessoais dos indivíduos, também conhecidas por know-how, que se relaciona com certo tipo de conhecimento profundamente enraizado na ação e no envolvimento dos indivíduos para com um contexto específico em determinadas profissões, tecnologias, mercados, ou até mesmo atividades de um grupo ou equipe de trabalho, e a cognitiva, que inclui diversos elementos como emoções, crenças, valores, atitudes, esquemas, competências e intuições.

Nessa mesma linha, Davenport e Prusak (1998) destacam o papel cognitivo do sujeito-conhecedor também para o conhecimento explícito. Os autores destacam o que Polanyi denominava "ferramentas cognitivas", ou seja, elementos explícitos, como representações abstratas, documentos, rotinas, etc., que visam permitir 
a ação humana intencional, mas que não podem ser interpretadas per se. Essas ferramentas cognitivas exigem o julgamento pessoal de um agente humano, um leitor especializado, que as relaciona e as aplica ao mundo (POLANYI, 1966).

Esses diversos elementos, que podemos designar como formadores das estruturas cognitivas, estão incorporados aos indivíduos, definindo, assim, a forma de agir e de se comportar, constituindo um filtro por meio do qual percebem a realidade. Com dificuldade de serem articulados por palavras, os elementos de ordem cognitiva acabam moldando a forma como percebemos o mundo e seus significados.

Da mesma forma que Nonaka e Takeuchi (1995), Nonaka (1991) agrega à dimensão epistemológica do conhecimento tácito, a dimensão de gestão. A comunicação e a integração das particularidades de um conhecimento tácito ocorrem por intermédio de seus significados. Esse campo de estudos se desenvolve com a denominação sense-making e circunscreve seu campo de investigação na questão dos processos de criação de sentido.

Para Weick (1995), a construção do sentido (sense-making) é uma atividade central na construção da organização e do seu ambiente. Ao longo do tempo, as estruturas cognitivas dos indivíduos tornam-se parte de uma visão do mundo socialmente reforçada. No contexto organizacional isso indica que a natureza cíclica de determinada atividade implica que os aspectos materiais e cognitivos do negócio devem estar consistentemente entrelaçados. Já para Dervin (1983), o sense-making é um método que busca uma lacuna e a ligação entre a situação e a ajuda necessária para compreendê-la. Quando o indivíduo identifica uma necessidade de informação e percebe uma lacuna entre o estado atual e o desejado, então, terá que suprir essa necessidade, buscando informações basicamente em quatro fontes: pessoais, comerciais, públicas ou experimentais.

$\mathrm{Na}$ área da contabilidade, Boland Júnior (1984) realizou experimentos de sense-making com gestores a partir de relatórios de contabilidade que foram preparados para descrever um cenário futuro fictício, mas plausível para uma organização. Uma série de direções futuras alternativas que a organização poderia ter seguido e diferentes tipos de organização que ela poderia ter se tornado serviram de base para a criação dos relatórios contábeis. A experiência cognitiva e emocional dos gestores participantes da pesquisa sugere que a prática de exercícios de sensemaking pode melhorar o processo de investigação e de organização das informações contábeis nos estágios iniciais de planejamento.

Nessa mesma linha, Tillmann e Goddard (2008) demonstraram que a utilização das técnicas de diálogo do sense-making contribuiu positivamente para o 
crescimento do know-how dos contadores, influenciando diretamente no contexto estratégico. Os autores também relatam que a construção do sentido, o sense-making, nos processos desenvolvidos pelos contadores, impactou de forma positiva no conjunto das informações e que isso tem auxiliado os clientes internos e externos nas tomadas de decisões. Já Heidmann, Schäffe e Strahringer (2008) abordam a relação entre sense-making e contabilidade sob a perspectiva interpretativa do processamento da informação e afirmam que os sistemas de contabilidade gerencial fornecem um contexto de informação que é necessário para o sense-making estratégico.

Assim, mesmo que estudos anteriores revelem interfaces entre sense-making e contabilidade, ainda há espaço para avanços no sentido de melhor compreender o papel do conhecimento tácito nessa interface, principalmente nas perspectivas técnica e cognitiva. Segundo pesquisa realizada por Puusa e Eerikäinen (2008), comportamentos com base na intuição e nos relacionamentos pessoais podem representar um tipo de conhecimento tácito cuja natureza pode variar. Para fazer emergir esse conhecimento, pessoas são estimuladas a refletirem sobre os meios para a transferência de conhecimento tácito ou de como torná-lo visível. Nessa tarefa, fazer perguntas, como propõe o sense-making, é essencial. Por isso, no caso do presente estudo, o sense-making é ao mesmo tempo quadro teórico e orientação metodológica para o resgate do conhecimento tácito, conforme apresentado a seguir.

\section{A PESQUISA}

O conhecimento tácito, enquanto dimensão dos estudos em gestão do conhecimento, ainda é um campo relativamente recente, o qual não é ainda considerado como circunscrito, além de não ser possível se estabelecer um paradigma teórico que o defina enquanto objeto.

Apesar do interesse cada vez maior de organizações em projetos e iniciativas em Gestão do Conhecimento, assim como o número crescente de publicações, eventos e cursos especializados, ainda prevalece a falta de consistência sobre os fundamentos teórico-metodológicos centrais que configurem um referencial sobre o campo. Uma base teórica referencial consolidada é fundamental para a legitimação e consolidação da área como conhecimento científico. (SANTOS; DOS REIS, 2010 , p. 4). 
Por isso, o presente trabalho é um estudo exploratório que se apoia no paradigma qualitativo de pesquisa e utiliza a análise de conteúdo como técnica de análise. O Esquema 1 representa as principais etapas da pesquisa: a primeira etapa do sense-making, quando foram realizadas as entrevistas piloto, os questionamentos iniciais para identificar as empresas que adotam a prática de elaboração de relatórios e a apresentação de resultados e, finalmente, a elaboração e a coleta de dados por meio do roteiro elaborado a partir das categorias de ordem técnica e cognitiva; a segunda etapa da análise de conteúdo ocorreu quando foi realizada a configuração do MAXqda a partir das categorias estabelecidas a priori, a elaboração da matriz de estimação e, por fim, a geração de tabelas e gráficos para suportar a análise do conteúdo.

Como contribuição, este artigo busca associar o sense-making ao conhecimento tácito em um campo tecnicamente especializado e denso, o da contabilidade. Uma vez aplicadas as técnicas de entrevista do sense-making, o conhecimento tácito revelado e organizado a partir dos elementos de natureza técnica e cognitiva podem indicar que um campo técnico não prescinde da capacidade de interpretação e análise na construção de suas práticas. Assumir a dimensão interpretativa nas práticas e produtos contábeis os legitimam como subsídios ao processo decisório e, portanto, às estratégias organizacionais (HEIDMANN; SCHÄFFER; STRAHRINGER, 2008).

Esquema 1 - Estrutura da pesquisa

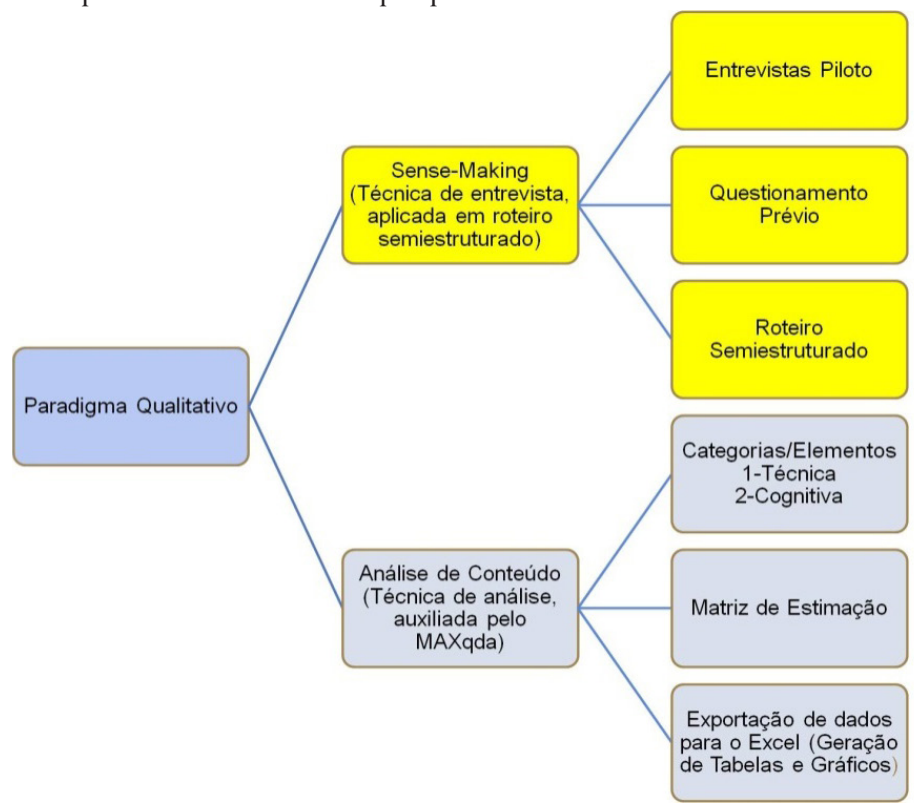

Fonte: os autores. 
Como técnica de entrevistas, foi utilizado o triângulo do sense-making pesquisado por Dervin (1983), que utiliza os fatos para organizar a realidade e, dessa maneira, colocar a informação dentro do seu contexto. Vale ressaltar que o interesse acadêmico deste estudo reside também na possibilidade de se verificar a aplicabilidade da associação do método de análise de conteúdo com as técnicas do sense-making, para resgatar os conhecimentos tácitos identificados nos processos específicos de elaboração de relatórios gerenciais e apresentação de resultados aos clientes das organizações contábeis entrevistadas.

\subsection{COLETA DE DADOS}

A coleta de dados ocorreu por meio da realização de entrevistas com um roteiro semiestruturado baseado na técnica de diálogo do sense-making (situaçãolacuna-ajuda) conforme o Quadro 1. Foram entrevistados os gestores das organizações contábeis, havendo, anteriormente, um questionamento sobre os tipos mais comuns de relatórios gerenciais elaborados e suas demais atividades, com respostas de sim ou não, a fim de constar se a organização contábil desenvolvia essas práticas, para assim prosseguir a entrevista. O roteiro foi testado em duas entrevistas pilotos, com contadores voluntários de outras organizações contábeis que não fazem parte desta pesquisa. Após a realização da primeira entrevista, alguns questionamentos foram ajustados, com o objetivo de provocar narrativas de experiências vivenciadas pelos entrevistados de acordo com a técnica de entrevista do sense-making. 
Quadro 1 - Roteiro Semiestruturado (situação-lacuna-ajuda)

\begin{tabular}{|c|c|}
\hline 01 & $\begin{array}{l}\text { Que erros são mais comumente identificados no processo de elaborar relatórios } \\
\text { gerenciais e de apresentar os resultados aos seus clientes? O que pode ser feito para } \\
\text { minimizá-los? }\end{array}$ \\
\hline 02 & $\begin{array}{l}\text { Quais são as habilidades funcionais e emocionais requeridas para desenvolver essas } \\
\text { atividades? O que pode ser feito para desenvolvê-las? }\end{array}$ \\
\hline 03 & $\begin{array}{l}\text { Que informações e conhecimentos tácitos são desenvolvidos pelo contador durante } \\
\text { a execução dessas atividades? }\end{array}$ \\
\hline 04 & $\begin{array}{l}\text { Quais são as principais dificuldades encontradas pelos atuais e/ou novos contado- } \\
\text { res da organização, no desempenhar dessas atividades? O que pode ser feito para } \\
\text { minimizá-las? }\end{array}$ \\
\hline 05 & $\begin{array}{l}\text { Que tipos de perguntas são feitas pelos clientes ao término das apresentações dos } \\
\text { resultados? E quando isso ocorre, as respostas estão nos relatórios gerenciais? Ou } \\
\text { precisam ser interpretadas pelo contador? }\end{array}$ \\
\hline 06 & $\begin{array}{l}\text { Que alterações podem ser implementadas nos relatórios gerenciais e na sua } \\
\text { apresentação, para que o cliente tenha amplo entendimento da apresentação dos } \\
\text { resultados? }\end{array}$ \\
\hline 07 & $\begin{array}{l}\text { Em razão da natureza dos resultados apresentados aos clientes, positivos ou nega- } \\
\text { tivos, o comportamento emocional do contador e do cliente apresenta alterações? } \\
\text { De que tipo? }\end{array}$ \\
\hline 08 & $\begin{array}{l}\text { Quais foram as experiências e circunstâncias vivenciadas durante as reuniões? } \\
\text { (Questionamentos, reclamações, comentários). Se ocorreram, estão registradas de } \\
\text { alguma forma? }\end{array}$ \\
\hline 09 & $\begin{array}{l}\text { Descreva como foi realizada uma apresentação dos resultados a um cliente que se } \\
\text { recorde, que lhe marcou ou que tenha lhe chamado a atenção. }\end{array}$ \\
\hline 10 & $\begin{array}{l}\text { Comente qual é a sequência ou como são as etapas e os processos do fluxo dos } \\
\text { serviços do setor contábil, até o momento de elaborar os relatórios gerenciais e } \\
\text { apresentá-los aos clientes. }\end{array}$ \\
\hline
\end{tabular}

Fonte: os autores

A finalidade do roteiro não foi a de obter dados técnicos de procedimentos contábeis, mas de provocar narrativas que revelassem dimensões tácitas agregadas a práticas de elaboração de relatórios e apresentação de resultados. Assim, a confiabilidade do conteúdo obtido com as entrevistas pode ser avaliada a partir do seu uso fundamentado em relação ao problema de pesquisa e aos objetivos do estudo na análise apresentada a seguir (CLARKE, 2002). Também buscamos a confiabilidade ao desenvolvermos um roteiro que possa ser aplicado em pesquisas 
semelhantes, cujos resultados estejam voltados ao resgate do conhecimento tácito associado a práticas contábeis (FLICK, 2008).

Das 19 organizações contábeis certificadas, 11 participaram da pesquisa. Constatando que a organização contábil elaborava relatórios gerenciais e os apresentava aos seus clientes, foram realizadas as entrevistas com as técnicas do triângulo do sense-making (situação-lacuna-ajuda). As narrativas foram gravadas em arquivos de áudio, com ciência e autorização dos participantes, e, posteriormente, transcritas na sua íntegra no editor de textos Word e importadas para o software MAXqda (Software for Qualitative Data Analysis).

$\mathrm{Na}$ fase de análise, a finalidade foi identificar, por meio das narrativas, as três partes do triângulo do sense-making, conforme Dervin (1983), alinhadas como categorias de análise, de acordo com Bardin (1977), mediante a aplicação de um roteiro semiestruturado com 10 questionamentos, conforme conforme o Quadro 2, buscando identificar:

a) a situação, ou seja, o que está se manifestando;

b) "gap", que é aquilo sobre o qual se deseja ter uma resposta, o que não está compreendido ou que tipo de conhecimento falta, ou seja, uma lacuna; c) a ajuda, o que pode ser feito.

$\mathrm{Na}$ presente pesquisa, a técnica de entrevista baseada no sense-making permitiu provocar narrativas dos entrevistados, por meio das perguntas realizadas durante as entrevistas e efetivamente muitas repetições ocorreram, gerando um vasto material de texto. Em cada resposta obtida, foi possível identificar a visão do entrevistado. Em vez de criticar ou corrigir, a entrevista foi organizada por intermédio de fala em triângulos (situação-lacuna-ajuda). Assim, respostas obtidas foram lançadas em uma grade mista, tendo como unidades de análise expressões, palavras e verbos. Posteriormente, realizou-se a análise de conteúdo com procedimentos interpretativos e associação aos conhecimentos tácitos resgatados.

\subsection{TÉCNICA DE ANÁLISE}

No caso da presente pesquisa, para viabilizar a análise de conteúdo, foi utilizado o software MAXqda, que agilizou e qualificou a análise do conteúdo das entrevistas. O MAXqda é um software projetado para auxiliar na análise qualitativa 
de dados de textos, multimídia e análise em instituições acadêmicas, científicas e de negócios. Como principal característica, o MAXqda permite importar documentos de diversos editores de texto, sem a necessidade preliminar de pré-formatação, conforme utilizado em estudos realizados por Klippel et al. (2004) e Lage (2011). O MAXqda possui diversos recursos, entre eles foram utilizados para esta pesquisa os recursos de formatação e edição para realizar ajustes nos documentos importados, bem como o recurso para concentrar as palavras similares, agrupando-as em uma única palavra-chave. O recurso de indexação foi utilizado para verificar as palavras mais utilizadas, com frequência igual ou superior a seis menções pelos entrevistados, relacionadas às características das categorias dos elementos de ordem técnica e cognitiva pesquisados, para auxiliar na identificação dos conhecimentos tácitos a serem resgatados. Também foi utilizado o recurso das funcionalidades automáticas para análise do conteúdo, que permitiu codificar os diversos segmentos das entrevistas, classificados por meio da matriz de estimação com sistema de códigos, nas categorias e sub-categorias dos elementos de ordem técnica e cognitiva, conforme o Quadro 2. Esse recurso facilitou a organização do registro das falas segundo as categorias de análise estabelecidas a partir de Nonaka (1994), Davenport e Prusak (1998), Puusa e Eerikäinen (2008) e Tillmann e Goddard (2008).

Quadro 2 - Categorias de análise dos elementos de ordem técnica e cognitiva

1-Elementos de ordem Técnica - Capacidades informais

1.1 Habilidades adquiridas (Know-How)

1.2 Competências pessoais desenvolvidas

2 Elementos de ordem Cognitiva - Forma de perceber o mundo

2.1 Aspectos Culturais - Crenças, valores, comportamentos

2.2 Aspectos Emocionais - Atitudes, intuições, percepções, esquemas, modelos mentais

Fonte: adaptado de Polanyi (1966) e Nonaka (1994).

Os segmentos, uma vez classificados, foram exportados para uma planilha eletrônica do Excel, que permitiu a identificação e o resgate dos conhecimentos da dimensão tácita dos elementos de ordem técnica e cognitiva. Em seguida, foi verificada a frequência dos verbos mencionados, que indicaram as ações mais mencionadas dos entrevistados. 


\subsection{PARTICIPANTES}

Foram estudadas 11 organizações contábeis associadas ao Sescon-Serra Gaúcha, entre as 19 que implataram o Programa de Qualidade Necessária Contábil (PQNC), categoria ouro, oficializada por meio da entrega do selo de qualidade contábil em 31 de maio de 2011. O PQNC é um Programa de certificação de qualidade desenvolvido especificamente para o segmento contábil pela Directiva Consultoria, a partir da Associação Brasileira de Normas Técnicas (ABNT, NBR ISO 9001), e que tem como filosofia principal o Comprometimento Total com o Cliente (CTC). Foram entrevistados os gestores das organizações contábeis entre agosto e setembro de 2011, conforme consta no Quadro 3.

Quadro 3 - Informações sobre o perfil dos entrevistados participantes (continua)

\begin{tabular}{|c|c|c|c|c|c|}
\hline $\begin{array}{l}\text { Códi- } \\
\text { go da } \\
\text { organi- } \\
\text { zação } \\
\text { contá- } \\
\text { bil do } \\
\text { entre- } \\
\text { vistado }\end{array}$ & Sexo & Idade & $\begin{array}{l}\text { Nível de formação na } \\
\text { área Contábil } \\
\text { (Técnico, Graduação, } \\
\text { Especialização) }\end{array}$ & $\begin{array}{c}\text { Tempo } \\
\text { de atu- } \\
\text { ação na } \\
\text { área } \\
\text { (em } \\
\text { anos) }\end{array}$ & $\begin{array}{l}\text { Tempo } \\
\text { como } \\
\text { gestor } \\
\text { Contá- } \\
\text { bil }\end{array}$ \\
\hline 01 & Masculino & 57 & $\begin{array}{l}\text { Técnico em Contabilidade } \\
\text { Graduação em Ciências } \\
\text { Contábeis }\end{array}$ & 37 & 25 \\
\hline 03 & Feminino & 33 & $\begin{array}{l}\text { Técnico em Contabilidade } \\
\text { Graduação em Ciências } \\
\text { Contábeis } \\
\text { Especialização em Controladoria }\end{array}$ & 10 & 5 \\
\hline 04 & Feminino & 30 & $\begin{array}{l}\text { Técnico em Contabilidade } \\
\text { Graduação em Ciências } \\
\text { Contábeis } \\
\text { Especialização em Gestão } \\
\text { Financeira }\end{array}$ & 12 & 4 \\
\hline 05 & Masculino & 51 & $\begin{array}{l}\text { Graduação em Ciências } \\
\text { Contábeis }\end{array}$ & 30 & 21 \\
\hline
\end{tabular}


(conclusão)

\begin{tabular}{|c|c|c|c|c|c|}
\hline $\begin{array}{l}\text { Códi- } \\
\text { go da } \\
\text { organi- } \\
\text { zação } \\
\text { contá- } \\
\text { bil do } \\
\text { entre- } \\
\text { vistado }\end{array}$ & Sexo & Idade & $\begin{array}{l}\text { Nível de formação na } \\
\text { área Contábil } \\
\text { (Técnico, Graduação, } \\
\text { Especialização) }\end{array}$ & $\begin{array}{c}\text { Tempo } \\
\text { de atu- } \\
\text { ação na } \\
\text { área } \\
\text { (em } \\
\text { anos) }\end{array}$ & $\begin{array}{l}\text { Tempo } \\
\text { como } \\
\text { gestor } \\
\text { Contá- } \\
\text { bil }\end{array}$ \\
\hline 07 & Feminino & 53 & $\begin{array}{l}\text { Graduação em Ciências } \\
\text { Contábeis } \\
\text { Especialização em Gestão de } \\
\text { Custos }\end{array}$ & 30 & 18 \\
\hline 08 & Masculino & 45 & $\begin{array}{l}\text { Técnico em Contabilidade } \\
\text { Graduação em Ciências } \\
\text { Contábeis }\end{array}$ & 25 & 10 \\
\hline 11 & Feminino & 29 & $\begin{array}{l}\text { Técnico em Contabilidade } \\
\text { Graduação em Ciências } \\
\text { Contábeis } \\
\text { Especialização em Gestão de } \\
\text { Custos }\end{array}$ & 10 & 3 \\
\hline 12 & Feminino & 35 & $\begin{array}{l}\text { Graduação em Ciências } \\
\text { Contábeis } \\
\text { Especialização em Controladoria }\end{array}$ & 12 & 8 \\
\hline 14 & Masculino & 62 & $\begin{array}{l}\text { Graduação em Ciências } \\
\text { Contábeis } \\
\text { Especialização em Gestão } \\
\text { Financeira }\end{array}$ & 42 & 31 \\
\hline 17 & Masculino & 65 & $\begin{array}{l}\text { Graduação em Ciências } \\
\text { Contábeis }\end{array}$ & 40 & 35 \\
\hline 19 & Feminino & 54 & $\begin{array}{l}\text { Técnico em Contabilidade } \\
\text { Graduação em Ciências } \\
\text { Contábeis } \\
\text { Especialização em Controladoria }\end{array}$ & 30 & 22 \\
\hline
\end{tabular}

Fonte: os autores.

Vale ressaltar que o Sescon-Serra Gaúcha conta com 256 organizações contábeis em sua base territorial, distribuídas em 14 municípios, como segue: André da Rocha, Antônio Prado, Campestre da Serra, Carlos Barbosa, Caxias do Sul, Farroupilha, Flores da Cunha, Garibaldi, Ipê, Monte Alegre dos Campos, Nova Pádua, Nova Roma do Sul, Protásio Alves e São Marcos (SESCON, 2011). 


\section{RESULTADOS E ANÁLISE}

O conhecimento tácito se manifestou nas narrativas dos entrevistados tanto nos elementos de ordem técnica quanto de ordem cognitiva. $O$ triângulo do sensemaking (situação-lacuna-ajuda) provocou entre os entrevistados uma narrativa mais detalhada de suas atividades e fez emergir o conhecimento tácito internalizado, desenvolvido durante a repetida execução das atividades de elaborar relatórios gerenciais e apresentação dos resultados aos clientes. Esse resultado remete à afirmação de Polanyi (1966) de que o conhecimento é socialmente construído e tem como base a experiência pessoal de cada indivíduo sobre a realidade em que está inserido.

A relação dos elementos de ordem técnica com a elaboração dos relatórios se manifestou na padronização e/ou regramentos nas etapas que compõem o processo de sua construção. Nesses elementos, as técnicas do sense-making contribuíram para resgatar, por meio da análise de conteúdo das narrativas dos entrevistados, a sensibilidade de percepção dos entrevistados quanto ao ambiente em que estão inseridos, os cenários e suas variações e os diferentes comportamentos e necessidades dos seus clientes.

As diversas falas forneceram condições para elaborar uma modelagem das quatro etapas identificadas nos processos do setor contábil, conforme o Esquema 2, o qual apresenta, por intermédio de uma sequência lógica, as atividades desenvolvidas e sua associação a uma tomada de decisão, representada pela figura geométrica de um losango.

Esquema 2 - Modelagem das quatro etapas identificadas dos processos contábeis, utilizando o Business Process Modeling Notation (BPMN)

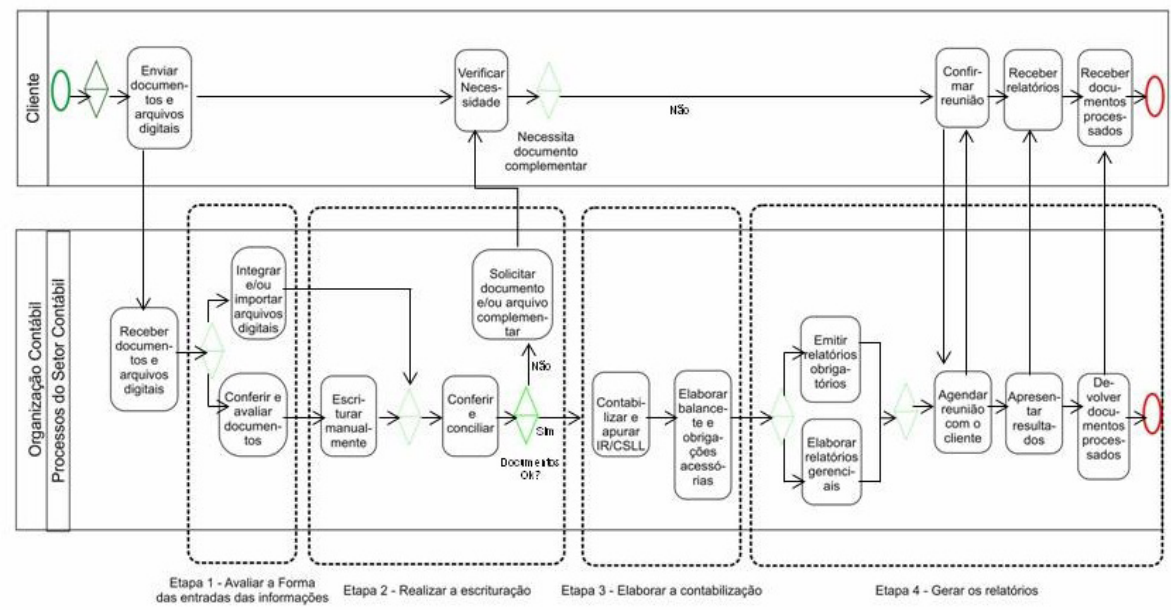

Fonte: os autores. 
A partir da verificação da integração da fase de elaboração e de geração dos relatórios por meio da modelagem, foi possível avançar na análise dos resultados no sentido de verificar os conceitos e as categorias presentes nas falas.

Inicialmente, foi realizada a codificação aberta nos textos das entrevistas transcritas. Esse processo ocorre a partir de conceitos e categorias identificados nas falas. Suas propriedades e dimensões são descobertas nos dados e constituem blocos de construção de teoria e, portanto, a primeira tarefa é abrir os dados para revelar e nomear esses conceitos (STRAUSS; CORBIN, 1998). Posteriormente, foram extraídas quatro subcategorias, agrupadas em duas categorias definidas a partir dos elementos de ordem técnica e cognitiva da dimensão tácita.

O conhecimento tácito permeia e, muitas vezes, define as práticas profissionais de forma não consciente, ou seja, o sujeito aprende com as experiências vividas e vai integrando esse aprendizado nas suas práticas ao longo de sua vida profissional. Assim, ao resgatar as práticas de elaboração de relatórios e apresentação dos resultados contábeis, foi possível analisar quais elementos do conhecimento tácito predominam e como eles se manifestam no conteúdo das falas dos entrevistados, conforme o Quadro 4.

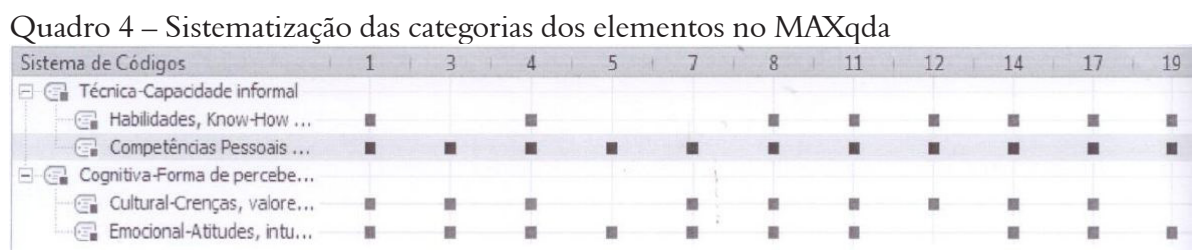

Fonte: os autores.

O resgate do conhecimento tácito foi organizado por meio do recorte de segmentos da fala dos 11 entrevistados, que, uma vez reunidos, possibilitaram a interpretação agrupada por categorias dos elementos.

\subsection{ANÁLISE DOS ELEMENTOS DE ORDEM TÉCNICA: CAPACIDADES INFORMAIS}

São compostos pelas habilidades adquiridas e pelas competências desenvolvidas pelo contador, que foram classificadas após o seu resgate nas narrativas das entrevistas 
realizadas. Também foram identificadas as ações baseadas na experiência profissional, que, associadas às práticas, fundamentam o conhecimento tácito.

\subsubsection{Habilidades adquiridas (Know-How)}

A percepção do entorno, das situações vivenciadas e seus desdobramentos e consequências demonstrou ser uma habilidade central para os entrevistados. Tal percepção pode ser estimulada e conduzida, mas é também fruto da experiência dos entrevistados, conforme pode ser percebido nas falas a seguir:

$\mathrm{Na}$ apresentação dos relatórios estabelecemos uma relação com o contexto atual, com períodos anteriores, buscando apresentar para o cliente a evolução ou retração do seu negócio, comparando com o segmento que está inserido aliado às tendências do mercado e da economia. (E3).

Ressaltamos nos relatórios e na apresentação, as sazonalidades do segmento e as diferentes margens dos diversos produtos, mercadorias e serviços, e seu impacto nos resultados. Fazer o cliente entender aonde foi aplicado o resultado do seu negócio é vital. (E6) (informações verbais).

\subsubsection{Competências pessoais desenvolvidas}

A sensibilidade de perceber o ambiente, os cenários e suas variações, dos diferentes comportamentos e necessidades dos clientes, demonstrou ser uma habilidade comum entre os entrevistados. A experiência dos entrevistados contribui para uma percepção fina das situações, o que pode ser o diferencial para a satisfação das reais necessidades dos clientes.

O contador também deve entender a forma que o cliente administra o seu negócio, para poder avaliar as consequências disso no patrimônio da empresa e dos seus sócios. (E5).

[...] buscando perceber o que mais lhe interessa saber e o que o cliente não consegue entender, para assim ir adequando e aperfeiçoando a forma de elaborar os relatórios e a maneira de apresentar os resultados [...] (E11).

[...] para que o cliente passe a cada reunião ter um entendimento mais amplo da relação da contabilidade com a gestão do seu negócio, estreitando assim cada vez mais o relacionamento com o contador, que cada vez mais nessas condições, passa a ser um parceiro de negócios [...] (E17) (informaçõs verbais). 


\subsection{ANÁLISE DOS ELEMENTOS DE ORDEM COGNITIVA}

Foram identificados aspectos culturais e emocionais do contador, além de ações e comportamentos decorrentes da experiência do profissional, que, associadas às suas práticas e percepções, também fundamentam a dimensão tácita do conhecimento.

\subsubsection{Aspectos culturais - crenças, valores, comportamentos}

$\mathrm{Na}$ análise do conteúdo das entrevistas foi possível identificar que são convergentes os valores mencionados pelos profissionais da contabilidade e que estes influenciam diretamente nos seus comportamentos. Tais valores dizem respeito à constante busca por um trabalho qualificado e principalmente correto; demonstram a preocupação e até a cumplicidade do contador em relação à melhor gestão do patrimônio dos seus clientes.

Entendo que sou a única pessoa que pode interpretar de forma adequada as informações contábeis para o cliente [...] (E1). Busco conquistar clientes que possuem um perfil de comportamento similar ao meu [...] (E19).

Procuro fazer o melhor e mais correto possível, buscando conquistar a empatia do cliente, sempre me fazendo entender [...] (E16).

Sei da minha responsabilidade perante o patrimônio do cliente [...] (E7).

Acredito que cliente que fala mal de outro contador não poderá ser um bom cliente $[\ldots](\mathrm{E} 9)$.

Percebo a necessidade de uma mudança cultural minha e do cliente, em função das normas internacionais [...] (E10).

Tenho que ter habilidade técnica e boa comunicação, ser claro, simples e objetivo, ter tranquilidade e paciência, para passar confiança ao cliente, deixando-o seguro e tranquilo [...] (E12). Acredito que o cliente que confia no trabalho aceita com mais facilidade as sugestões de mudança [...] (E13).

Minha realização pessoal é quando o cliente fica satisfeito com o seu serviço [...] (E8) (informações verbais). 


\title{
4.2.2 Aspectos emocionais - atitudes, intuições, percepções, esquemas, modelos mentais
}

As diversas percepções relatadas pelos entrevistados demonstram algumas de suas características pessoais e, principalmente, os seus objetivos como profissionais que buscam constantemente oferecer um trabalho diferenciado aos seus clientes. A maioria das atitudes demonstra o foco que os contadores entrevistados exercem em suas atividades.

\subsection{ANÁLISE DA FREQUÊNCIA DE PALAVRAS}

A análise foi realizada considerando apenas os verbos presentes na fala dos entrevistados. Esse critério se fundamenta no objeto da presente pesquisa, uma vez que, segundo Polany (1966), o processo interno de como funcionam nossas ações é tácito. Assim, foi considerado que as ações expressas nos verbos utilizados pelos entrevistados podem ser associadas às práticas profissionais e ao conhecimento tácito.

\begin{abstract}
Eu me envolvo com o cliente, que geralmente se torna amigo, vibrando com os bons resultados e se comovendo com resultados indesejados [...] (E2).

Crê na falta de comprometimento do cliente com a curacidade das informações fornecidas ao contador; embora que existam exceções [...] (E4).

Quando ocorrem divergências nos números apresentados, percebe que o cliente acha que o culpado é apenas o contador, e não quem passou a informação incorreta da empresa do cliente $[\ldots]$ (E14).

Crê que a maioria dos clientes o acha chato, por exigir as informações bem detalhadas e também pelo fato de não fechar os relatórios com documentação faltante [...] (E15).

Percebe que os clientes potenciais gostariam de ter as informações contábeis disponíveis em tempo real nas suas empresas, para a rápida tomada de decisão ou até que o contador estivesse mais tempo dentro da empresa [...] (E18).

Acredita que os clientes mais limitados não gostam de alterações frequentes nos modelos de relatórios apresentados nas reuniões [...] (E7) (informações verbais).
\end{abstract}


Inicialmente, foram identificadas 102 palavras relacionadas ao assunto pesquisado, que tiveram frequência igual ou superior a duas menções pelos entrevistados, entre 1992 palavras coletadas, relacionadas aos elementos de ordem técnica e cognitiva da dimensão tácita do conhecimento.

Em seguida, foi estabelecido como ponto de corte, a frequência igual ou superior a seis menções pelos entrevistados, perfazendo 44 entre as 102 palavras previamente selecionadas e relacionadas aos elementos de ordem técnica e cognitiva da dimensão tácita do conhecimento.

Quadro 5 - Frequência das palavras

\begin{tabular}{|l|r|l|r|l|r|}
\hline \multicolumn{1}{|c|}{ Palavra } & Frequência & Palavra & Frequência & \multicolumn{1}{|c|}{ Palavra } & Frequência \\
\hline Verdade & 28 & Realmente & 12 & Vertical & 9 \\
\hline Balanço & 19 & Pessoas & 11 & Demonstrar & 8 \\
\hline Interpretar & $\mathbf{1 9}$ & Prática & 11 & Empresário & 8 \\
\hline Reunião & 19 & Tranquilidade & 11 & Preocupado & 8 \\
\hline Gerenciais & 17 & Comparar & 10 & Receita & 8 \\
\hline Experiência & 14 & Controle & 10 & Reclamação & 7 \\
\hline Perguntar & 14 & Elaborar & $\mathbf{1 0}$ & Melhorar & 6 \\
\hline Dificuldade & 13 & Explicar & 10 & Perceber & 6 \\
\hline Escritório & 13 & Problema & 10 & Diretoria & 6 \\
\hline Gráficos & 12 & Prejuízo & 9 & Trabalha & \\
\hline Questionar & 12 & Surpreender & $\mathbf{9}$ & Verificar & \\
\hline Fonte: & & & & & \\
\hline
\end{tabular}

Fonte: os autores.

Posteriomente, foi verificada a frequência de verbos, conforme o Quadro 6. Os verbos classificados com o número 1 são os de ordem técnica e com o número 2 são os de ordem cognitiva do conhecimento tácito. Esse Quadro foi elaborado a partir das palavras com frequência igual e superior a 6 menções pelos entrevistados, conforme apresentado no Quadro 5. 
Quadro 6 - Frequência de verbos

\begin{tabular}{|c|c|c|c|c|c|}
\hline & Palavra & $\begin{array}{c}\text { Frequência } \\
\text { crescente }\end{array}$ & & Palavra & $\begin{array}{l}\text { Frequência } \\
\text { decrescente }\end{array}$ \\
\hline 1 & Verificar & 6 & 1 & Conhecer & 49 \\
\hline 2 & Perceer & 7 & 1 & Perguntar & 14 \\
\hline 1 & Melhorar & 7 & 1 & Questionar & 12 \\
\hline 2 & Demonstrar & 8 & 1 & Comparar & 10 \\
\hline 2 & Surpreender & 9 & 1 & Elaborar & 10 \\
\hline 2 & Explicar & 10 & 1 & Melhorar & 7 \\
\hline 1 & Elaborar & 10 & 1 & Verificar & 6 \\
\hline 1 & Comparar & 10 & 2 & Analisar & 95 \\
\hline 1 & Questionar & 12 & 2 & Apresentar & 38 \\
\hline 1 & Perguntar & 14 & 2 & Entender & 33 \\
\hline 2 & Interpretar & 19 & 2 & Interpretar & 19 \\
\hline 2 & Entender & 33 & 2 & Explicar & 10 \\
\hline 2 & Apresentar & 38 & 2 & Surpreender & 9 \\
\hline 1 & Conhecer & 49 & 2 & Demonstrar & 8 \\
\hline 2 & Analisar & 95 & 2 & Perceber & 7 \\
\hline & \multicolumn{4}{|l|}{ Total de verbos } & 15 \\
\hline & \multicolumn{4}{|l|}{ Total da frequência } & 327 \\
\hline 1 & \multicolumn{4}{|c|}{ Total de verbos relacionados a elementos de ordem técnica } & 7 \\
\hline 2 & \multicolumn{4}{|c|}{ Total de verbos relacionados a elementos de ordem cognitiva } & 8 \\
\hline 1 & \multicolumn{4}{|c|}{ Total da frequência dos verbos dos elementos de ordem técnica } & 108 \\
\hline 2 & \multicolumn{4}{|c|}{ Total da frequência dos verbos dos elementos de ordem cognitiva } & 219 \\
\hline
\end{tabular}

Fonte: os autores.

Destacam-se com o número 1 os sete verbos relacionados aos elementos de ordem técnica: conhecer, perguntar, questionar, comparar, elaborar, melhorar e verificar. E o número 2 indica os oito verbos relacionados aos elementos de ordem cognitiva: analisar, apresentar, entender, interpretar, explicar, surpreender, demonstrar e perceber.

Sobre a classificação do verbo conhecer nos elementos de ordem técnica, que poderia remeter aos elementos cognitivos, identificamos nas narrativas dos entrevistados que, ao mencionar o referido verbo, relacionaram-no ao contexto dos conhecimentos técnicos sobre as práticas contábeis.

Os verbos perguntar e questionar podem ser associados, pois possuem sentido semelhante. A presença do verbo elaborar estabelece a relação dos elementos de ordem técnica com a elaboração dos relatórios gerenciais. O Gráfico 1 apresenta a frequência dos verbos relacionados aos elementos de ordem técnica. 
Gráfico 1 - Frequência dos verbos relacionados aos elementos de ordem técnica

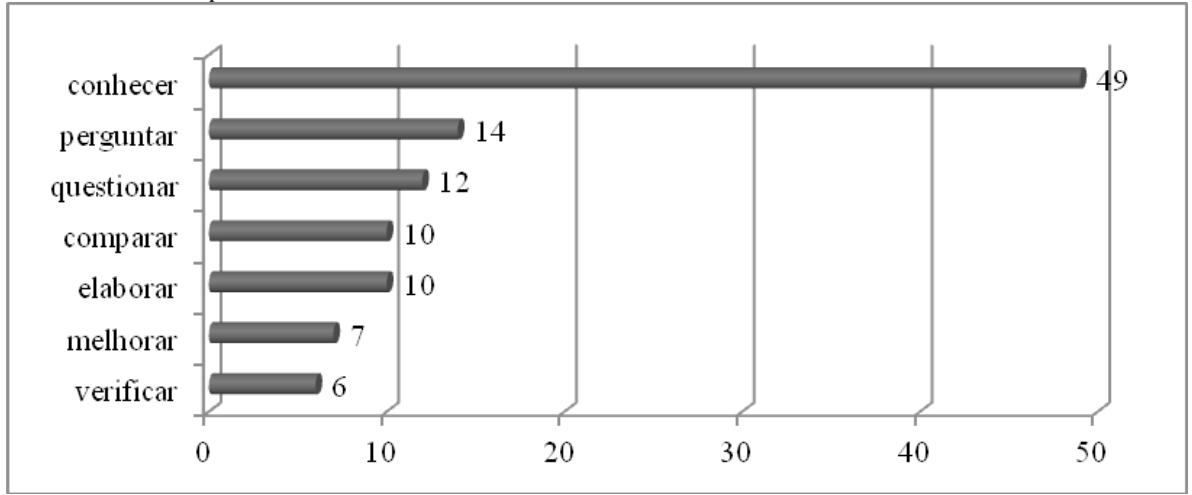

Fonte: os autores.

Nos elementos de ordem cognitiva, destaca-se a frequência do verbo analisar. Por definição, analisar pressupõe processos cognitivos de interpretação de diferentes informações associadas a contextos específicos. Percebe-se, então, um predomínio de elementos cognitivos na frequência dos verbos utilizados pelos entrevistados.

Outro aspecto importante da análise da frequência dos verbos diz respeito ao verbo apresentar que está associado ao verbo demonstrar, pois estabelece a relação dos elementos cognitivos com a apresentação dos resultados. O Gráfico 2 apresenta a frequência dos verbos relacionados aos elementos de ordem cognitiva.

Gráfico 2 - Frequência dos verbos relacionados aos elementos de ordem cognitiva

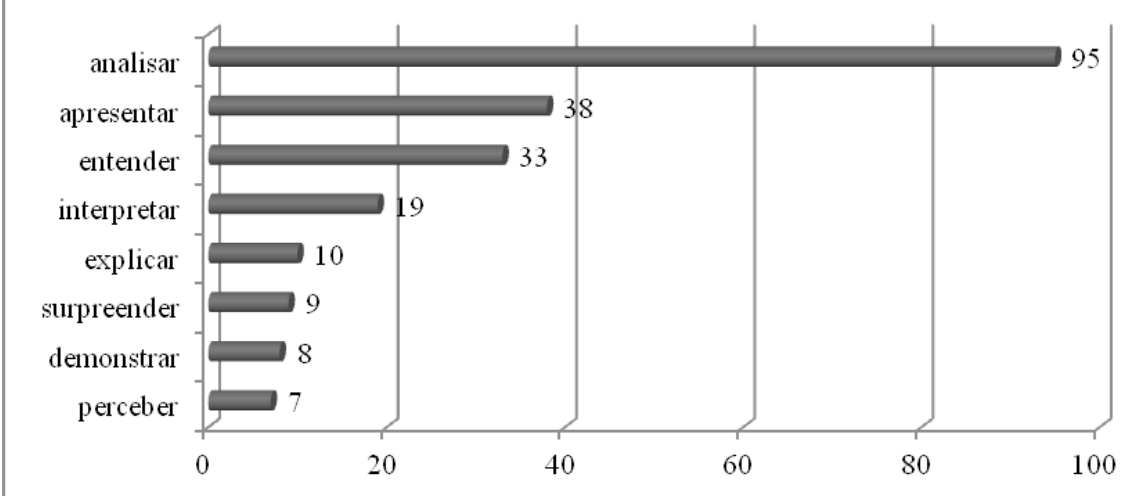

Fonte: os autores. 
Percebe-se nos Gráficos 1 e 2 que os verbos mais utilizados pelos entrevistados se alinham com o significado tanto dos elementos de ordem técnica quanto cognitiva do conhecimento tácito. Esse alinhamento indica a viabilidade de se utilizar tais elementos para se analisar o conhecimento que se acumula a partir das experiências e do sentido das práticas realizadas pelos sujeitos, mesmo que seja em atividades tão específicas e com alto grau de especialidade, como é a contabilidade.

A partir desses resultados, foi possível verificar que a relação dos elementos de ordem técnica com a elaboração dos relatórios se manifesta na padronização e/ ou regramentos nas etapas que compõem o processo de sua construção. Nesses elementos, as técnicas do sense-making contribuíram para resgatar, por meio da análise de conteúdo das narrativas dos entrevistados, a percepção dos entrevistados quanto ao ambiente em que estão inseridos, os cenários e suas variações e os diferentes comportamentos e necessidades dos seus clientes.

Foram resgatadas entre as capacidades informais dos elementos de ordem técnica sobre as habilidades adquiridas (Know-How), as percepções dos entrevistados do entorno, das situações vivenciadas e seus desdobramentos. Entre as competências pessoais, desenvolvidas durante o tempo de execução dessas atividades de elaborar relatórios gerenciais e apresentar os resultados aos clientes, foi também resgatada a sensibilidade que os entrevistados têm de perceber o ambiente, os cenários e suas variações, bem como os diferentes comportamentos e necessidades dos clientes. O desenvolvimento dessas experiências pode ser o diferencial para a satisfação dos clientes. Vale salientar que, a respeito de experiências, Davenport e Prusak (1998) comentam que o conhecimento adquirido por meio da experiência e que permanece em sua forma tácita nem sempre pode ser expressado por intermédio da linguagem, nem incorporado em ferramentas cognitivas, como documentos.

Os elementos de ordem cognitiva também permitiram um regaste efetivo do conhecimento tácito, principalmente nos aspectos emocionais, na percepção dos entrevistados sobre o envolvimento e a empatia do cliente, das responsabilidades em gerir as informações que venham a nortear as decisões dos clientes. Esses elementos se referem aos valores pessoais mencionados pelos profissionais da contabilidade que influenciam de forma direta os seus comportamentos.

A relação dos elementos de ordem cognitiva com a apresentação dos resultados aos clientes evidencia a subjetividade dos diferentes contextos que cada cliente está inserido em determinado momento. As ansiedades e incertezas fazem parte do pensamento do cliente, e conforme a intensidade dessas variáveis, a apresentação dos resultados pode ter seu enfoque condicionado. 
Além desses aspectos, as técnicas do sense-making contribuíram para resgatar, mediante a análise de conteúdo das narrativas dos entrevistados, a percepção sobre como as suas crenças, e seus valores éticos e morais influenciam no comportamento do profissional contábil, ou seja, os elementos cognitivos sobre o aspecto cultural. Nas diversas narrativas, percebeu-se a preocupação desses profissionais em realizar um trabalho correto e qualificado na elaboração dos relatórios gerenciais e na apresentação dos resultados aos seus clientes.

Foi possível também identificar a cumplicidade do contador em relação à melhor gestão do patrimônio dos seus clientes. Essa cumplicidade está relacionada a uma forma de evolução dos conhecimentos do contador, o que corresponde à afirmação de Dervin (1999) sobre o fato de que enquanto o indivíduo tiver a capacidade de construir significado, irá produzir a constante evolução dos seus conhecimentos.

Foram também resgatados os elementos cognitivos sobre o aspecto emocional dos entrevistados, suas atitudes, intuições, percepções, esquemas, modelos mentais, algumas de suas características pessoais e, principalmente, os seus objetivos como profissionais que buscam constantemente oferecer um trabalho diferenciado aos seus clientes. Conforme Wright (2008), pode-se encontrar novas fontes de conhecimento tácito; no caso de não conseguirmos administrá-lo, a alternativa é encontrar formas para obter esse conhecimento tácito identificado, de forma que possa ser útil para a promoção humana e para lucro.

Sobre esses aspectos pode-se perceber como o sense-making faz sentido para a contabilidade atualmente. Nesta pesquisa, graças a ele foi possível o resgate do conhecimento tácito na prática de elaboração de relatórios e na apresentação dos resultados aos clientes, sob os elementos de ordem técnica e cognitiva. Também constatamos que em algumas narrativas, os entrevistados, ao perceberem o seu entorno por meio dos questionamentos, recordaram-se de práticas que não utilizavam mais, ou seja, não lembravam que sabiam. Essas circunstâncias podem remeter à afirmação de Polanyi (1966, p. 4): “[...] sabemos mais do que podemos dizer.”

Enfim, se considerarmos que a elaboração de relatórios gerenciais e a apresentação dos resultados é uma prática que não é obrigatória e, portanto, considerada um diferencial para as organizações contábeis que as realizam, o conhecimento técnico e a capacidade de análise podem ser, então, os elementos que fundamentam tal diferencial. Com a presente pesquisa, pode-se perceber que as organizações contábeis podem direcionar os seus recursos buscando melhor desenvolver e explorar tais elementos, aprimorando a forma de elaborar os relatórios 
e apresentá-los aos seus clientes. Assim, pode-se ter ganho na produtividade e na qualidade dos seus serviços prestados.

\section{CONSIDERAÇÕES FINAIS}

A contabilidade atravessa um momento de mudanças, em especial nos seus últimos cinco anos em decorrência da implantação, por parte do fisco, do Sistema Público de Escrituração Digital (SPED) e, principalmente, em razão da harmonização e da convergência das normas contábeis brasileiras, aos padrões internacionais de contabilidade (IFRS), conforme o IASB. Para acompanhar essas mudanças, as organizações contábeis entrevistadas buscaram qualificar-se. Assim, adotaram o Programa de Qualidade Necessária Contábil (PQNC), que busca certificar o segmento contábil, baseado na Associação Brasileira de Normas Técnicas (ABNT, NBR ISO 9001). O PQNC tem como filosofia principal o Comprometimento Total com o Cliente (CTC), que busca elevar a qualidade dos processos, bem como alcançar melhores condições para atender às novas exigências fiscais nacionais (SPED) e normas internacionais (IFRS). Nesse quadro, a demanda pela informação contábil é crescente, disso a importância dos processos de elaboração de relatórios gerenciais e a apresentação dos resultados aos clientes.

O desafio, nesse contexto, e que se constituiu no problema desta pesquisa, foi o de buscar elementos de resposta para a questão de como identificar e analisar a dimensão tácita do conhecimento agregado às práticas contábeis, especificamente nos processos de elaborar relatórios gerenciais e apresentar resultados, de forma a contribuir para a evolução das boas práticas contábeis alinhadas ao padrão internacional vigente.

A utilização do sense-making proporcionou obter não apenas o registro das percepções dos entrevistados, mas também elementos sobre os conhecimentos tácitos mais utilizados pelos contadores envolvidos no processo contábil, especificamente na elaboração de relatórios gerenciais e na apresentação dos resultados aos seus clientes.

Ao resgatar as práticas de elaboração de relatórios e a apresentação dos resultados contábeis, foi possível analisar quais elementos do conhecimento tácito predominam e como eles se manifestam no conteúdo das falas dos entrevistados: a sensibilidade de perceber o ambiente, os cenários e suas variações e os diferentes comportamentos e necessidades dos clientes. A utilização do sense-making nas entrevistas demonstrou eficácia também ao resgatar características dos elementos 
cognitivos dos entrevistados, que foram convergentes quanto aos valores pessoais mencionados e sua influência nas práticas contábeis.

O MAXqda possibilitou uma melhor visualização da composição da estrutura das categorias dos elementos de ordem técnica e cognitiva, contribuindo de forma significativa para uma melhor classificação, das narrativas dos entrevistados, utilizando as técnicas do triângulo do sense-making.

Em consonância com a abordagem exploratória adotada na pesquisa, o sense-making foi eficaz para o resgate do conhecimento tácito e para a construção de proposições sobre as relações entre as variáveis e que podem se constituir em hipóteses resultantes desta pesquisa (FLICK, 2008; SAMPIERI; COLLADO; LUCIO, 2013):

a) as técnicas de diálogo do sense-making podem possibilitar a sistematização do resgate do conhecimento tácito no setor contábil e fundamentar a organização de uma base de conhecimento que pode ser compartilhada e consultada pelos membros da organização;

b) o conhecimento tácito, quando compartilhado, pode influenciar os processos contábeis pela via de suas práticas, e pode ser um elemento central para a inovação incremental nos processos contábeis. Porém, não é um processo espontâneo e por isso tem de ser provocado, ou seja, a influência do conhecimento tácito somente vai ocorrer à medida que for resgatado.

Assim, ao analisarmos o conteúdo das entrevistas, identificamos que as empresas contábeis preocupadas com a qualidade de seus serviços (PQNC) e com o Comprometimento Total com o Cliente (CTC) pautam suas práticas em ações de conhecer, perguntar, questionar, comparar, elaborar, melhorar e verificar (ordem técnica), e também de analisar, apresentar, entender, interpretar, explicar, surpreender, demonstrar e perceber (ordem cognitiva). A análise de tais verbos, associada às categorias relativas à sensibilidade de perceber o ambiente, os cenários e suas variações e os diferentes comportamentos e necessidades dos clientes, além da influência dos valores pessoais mencionados nas práticas contábeis, constitui-se em uma clara indicação dos aspectos a serem priorizados nas ações de qualidade de serviços e comprometimento com o cliente. Assim, ao considerar tais indicações procedentes da pesquisa, práticas contábeis de elaboração de relatórios e a apresentação dos resultados, podem estar melhor preparados para serem considerados pelos 
clientes das organizações contábeis subsídios ao processo decisório e à construção de estratégias gerenciais.

Em termos de perspectivas para estudos futuros, além das proposições mencionadas, um aprofundamento da análise sobre os elementos de ordem cognitiva do conhecimento tácito poderia produzir análises também sobre a dimensão comportamental associada ao resgate do conhecimento tácito.

\section{REFERÊNCIAS}

ANTUNES, M. T. P. Capital Intelectual. São Paulo: Atlas, 2000.

BARDIN, L. Análise de Conteúdo. Lisboa: Edições 70, 1977.

BEAGLEY, S.; TAYLOR, M.; BRYSON, J. R. Firms as Connected, Temporary Coalitions: Organisational Forms and the Exploitation of Intellectual Capital. The Electronic Journal of Knowledge Management, v. 7, p. 11-20, 2009. Disponível em: <http://www.ejkm.com/search/index.html?name=keyword\&value $=$ temporary\%20coalitions $>$. Acesso em: 21 jun. 2011.

BODA, G.; SZLÁVIK, P. Alternative Accounting to Manage Intellectual Capital. The Electronic Journal of Knowledge Management, v. 5, p. 7-18, 2007. Disponível em: <http://www.ejkm.com/volume5/issue1/p7> . Acesso em: 20 jun. 2011.

BOLAND JÚNIOR, R. J. Sense-making of accounting data as a technique of organizational diagnosis. Management Science, v. 30, n. 7, p. 868-882, 1984.

BRÄNNSTRÖM, D.; GIULIANI, M. Intellectual Capital Valuation and IFRS3: A New Disclosure Opportunity. The Electronic Journal of Knowledge Management, v. 7, p. 21-30, 2009. Disponível em: < http://www.ejkm.com/ volume7/issue1/p21>. Acesso em: 19 maio 2011.

BRASIL. Decreto n. 6.022, de 22 de janeiro de 2007. Institui o Sistema Público de Escrituração Digital (SPED). Diário Oficial da União, Brasília, DF, 22 jan. 2007a. Edição extra. Disponível em: < http://www.presidencia.gov.br/ccivil_03/_ Ato2007-2010/2007/Decreto/D6022.htm >. Acesso em: 16 dez. 2011.

BRASIL. Lei n. 11.638, de 28 de dezembro de 2007. Altera e revoga dispositivos da Lei n. 6.404, de 15 de dezembro de 1976, e da Lei n. 6.385, de 07 de dezembro de 1976, e estende às sociedades de grande porte disposições relativas à elaboração e divulgação de demonstrações financeiras. Diário Oficial da União, Brasília, DF, 28 dez. 2007b. Edição extra. Disponível em: < http://www.presidencia.gov.br/ ccivil_03/_Ato2007-2010/2007/Lei/L11638.htm >. Acesso em: 16 dez. 2011. 
CLARKE, S. Learning from experience: psycho-social research methods in the social sciences. Qualitative Research, v. 2, n. 2, p. 173-194, 2002.

\section{COMITÊ DE PRONUCIAMENTOS CONTÁBEIS. Pronunciamento}

Técnico CPC 01 (R1), de 06 de agosto de 2010. Disponível em: < http://www. cpc.org.br/pdf/CPC01R1.pdf>. Acesso em: 16 dez. 2011.

DAVENPORT, T. H.; PRUSAK, L. Conhecimento empresarial: como as organizações gerenciam o seu capital intelectual. 4. ed. Tradução Lenke Peres. Rio de Janeiro: Campus, 1998.

DERVIN, B. An overview of sense-making research: Concepts, methods and results to date. Texas: International Communication Association Annual Meeting, 1983.

DERVIN, B. On studying information seeking methodologically: The implications on connecting metatheory to method. Information Processing and Management, 1999.

DRUCKER, P. F. Uma era de descontinuidade. Tradução Brandão Azevedo. Rio de Janeiro: Zahar, 1970.

FLICK, U. Uma introdução à pesquisa qualitativa. 3. ed. Porto Alegre: Bookman, 2008.

GARCIA-PEREZ, A.; MITRA, A. Tacit Knowledge Elicitation and Measurement in Research Organisations: a Methodological Approach. The Electronic Journal of Knowledge Management, v. 5, p. 373-386, 2008. Disponível em: < http:// www.ejkm.com/main.html>. Acesso em: 12 nov. 2011.

GROPP, B. M. C.; TAVARES, M. P. Dimensões intangíveis: a relevância do conhecimento tácito em processos de inovação e sustentabilidade. In: CONFERÊNCIA INTERNACIONAL SOBRE INOVAÇÃO E GESTÃO, 6., 2009, São Paulo. Anais... São Paulo: Pontifícia Universidade Católica de São Paulo, 2009.

HEIDMANN, M.; SCHÄFFER, U.; STRAHRINGER, S. Exploring the role of management accounting systems in strategic sensemaking. Information Systems Management, v. 25, n. 3, p. 244-257, 2008.

IUDÍCIBUS, S. de. Teoria da Contabilidade. São Paulo: Atlas, 2000.

JIMES, C.; LUCARDIE, L. "Reconsidering the tacit-explicit distinction - A move toward functional (tacit) knowledge management". The Electronic Journal of Knowledge Management, v. 1, p. 23-32, 2003. Disponível em: < http://www. ejkm.com/main.html >. Acesso em: 11 nov. 2011. 
JOSHI, M.; UBHA, S. D. Intellectual Capital Disclosures: the Search for a new Paradigm in Financial Reporting by the Knowledge Sector of Indian Economy. Electronic Journal of Knowledge Management, v, 7, p. 575-582, 2009. Disponível em: <http://issuu.com/academic-conferences.org/docs/ejkm-volume7issue5-ticle207?mode=a_p > . Acesso em: 24 jun. 2011.

KLIPPEL, M. et al. A pesquisa em Administração com o uso de softwares QDA (Qualitative Data Analysis). In: SIMPÓSIO SOBRE EXCELÊNCIA EM GESTÃO E TECNOLOGIA, 1., 2004, Rio de Janeiro. Anais... Rio de Janeiro, 2004.

LAGE, M. C. Softwares do tipo CAQDAS e a sua contribuição para a pesquisa qualitativa em educação. Educação e Temática Digital, São Paulo, v. 12, n. 2, p. 42-58, 2011.

LOPES, I. T.; RODRIGUES, A. M. G. Intangible Assets Identification and Valuation - a Theoretical Framework Approach to the Portuguese Airlines Companies. The Electronic Journal of Knowledge Management, v. 5, p. 193202, 2007. Disponível em: < http://www.ejkm.com/volume5/issue2/p191>. Acesso em: 22 jun. 2011.

MINAYO, M. C. S. O desafio do conhecimento: pesquisa qualitativa em saúde. 8. ed. São Paulo: Hucitec, 2004.

NONAKA, I. Dynamic Theory of Organizational Knowledge Creation. Organization Science, v. 5, n. 1, p. 14-37, Feb. 1994.

NONAKA, I.; TAKEUCHI, H. Criação de conhecimento na empresa: como as empresas japonesas geram a dinâmica da inovação. Rio de Janeiro: Campus, 1997.

NONAKA, I.; TAKEUCHI, H. The knowledge-crating company: How Japanese companies create the dynamics of innovation. New York: Oxford University Press, 1995.

NONAKA, I. The knowledge-creating company. Harvard Business Review, p. 96-104, 1991.

PALÁCIOS, A. C. O processo de convergência das normas brasileiras de contabilidade com as normas internacionais. Revista do Conselho Regional de Contabilidade do Rio Grande do Sul, n. 1, maio 2010.

POLANYI, M. Personal Knowledge: Towards a post-critical philosophy. London: Routdedge \& Kegan Paul, 1958. 
POLANYI, M. The tacit dimension. London: Routdedge \& Kegan Paul, 1966. PUUSA, A.; EERIKÄINEN, M. "Is Tacit Knowledge Really Tacit?" Electronic Journal of Knowledge Management, v. 8, p. 307-318, 2008. Disponível em: <www.ejkm.com>. Acesso em: 03 nov. 2011.

SÁ, A. L. Teoria geral do conhecimento contábil. 1. ed. Belo Horizonte: IPAT - UNA: Artes Gráficas Siracusa, 1993.

SAMPIERI, R. H.; COLLADO, C. F.; LUCIO, P. B. Metodologia de Pesquisa. São Paulo: McGraw-Hill, 2010.

SINDICATO DAS EMPRESAS DE SERVIÇOS CONTÁBEIS, ASSESSORAMENTO, PERÍCIAS, INFORMAÇÕES E PESQUISAS DA REGIÃO SERRANA DO RIO GRANDE DO SUL - Serra Gaúcha. Caxias do Sul. Disponível em: < http://sesconserragaucha.com.br/>. Acesso em: 11 nov. 2011.

STRAUSS, A.; CORBIN, J. Basics of Qualitative Research: Techniques and Procedures for Developing Grounded Theory. Londres: Sage, 1998.

TILLMANN, K.; GODDARD, A.; LOPES A. Strategic management accounting and sense-making in a multinational. Management Accounting Research, v. 19, p. 80-102, 2008. Disponível em: < http://www.sciencedirect.com/science/article/ pii/S104450050700053 > . Acesso em: 16 ago. 2011.

VERGARA, S. C. Métodos de Pesquisa em Administração. 3. ed. São Paulo: Atlas, 2008.

WEICK, K. E. Sensemaking in organizations. Traducão Aline Vieira Malanovicz. Thousand Oaks: Sage Publications, 1995.

WRIGHT, H. Tacit Knowledge and Pedagogy at UK Universities; challenges for Effective Management. The Electronic Journal of Knowledge Management, v. 6, p. 49-62, 2008. Disponível em: < http:// www.ejkm.com>. Acesso em: 01 nov. 2011. 


\section{Como citar este artigo}

BERTOLLA, Fernando Luís; FACHINELLI, Ana Cristina. A dimensão tácita do conhecimento nas práticas contábeis: uma análise dos processos de elaboração e apresentação de relatórios em organizações contábeis. RACE, Revista de Administração, Contabilidade e Economia, Joaçaba: Ed. Unoesc, v. 14, n. 1, p. 3972, jan./abr. 2015. Disponível em: < http://editora.unoesc.edu.br/index.php/race>. Acesso em: dia/mês/ano.

Bertolla, F. L., \& Fachinelli, A. C. A. (2015). A dimensão tácita do conhecimento $\varangle$ nas práticas contábeis: uma análise dos processos de elaboração e apresentação de relatórios em organizações contábeis. RACE, Revista de Administração, Contabilidade e Economia, 14(1), 39-72. Recuperado em dia/mês/ano, de http://editora.unoesc.edu. br/index.php/race 
